\title{
Obituaries
}

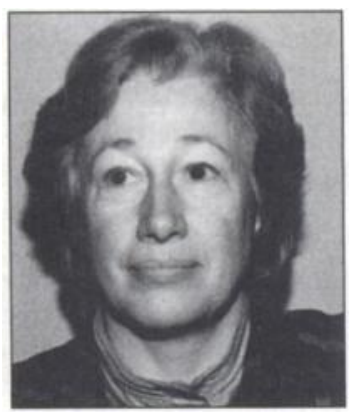

Mand Norman-Nott, formerly Consultant Psychotherapist, Royal Hampshire Hospital, Winchester

Psychiatry in the South of England, and particularly psychotherapy, have suffered a serious loss in the death of one of their most energetic and colourful practitioners, Maud NormanNott, who died on 1 August 1994. Not only had she been an active committee member of the South West Division of the College for many years, but she had taken a leading role in the running of the Winchester BMA, and was deeply involved in local schools and community bodies.

Maud was born in Holland at the beginning of the Second World War, and suffered considerable privation during the years of the Nazi occupation of the Netherlands. Her early childhood experiences influenced her choice of career, medicine, which she studied at the University of Leyden, graduating DR S Med 1966. Arts examen 1968, before coming to Oxford to study her chosen speciality, psychiatry. She gained the DPM in 1972 and the MRCPsych in 1973, proceeding to the fellowship in February 1990. It was at Oxford where she served at the Littlemore, Warneford and Park hospitals, that she met her husband, Peter, and where the first of her four children was born.

The family moved to Southampton in 1975 , and in 1982 Maud was appointed Consultant Psychotherapist to the Winchester and Basingstoke District. She was responsible for establishing the new Department of Psychotherapy at the Royal Hampshire County Hospital, Winchester. At the same time she was developing the psychotherapy services at Park Prewett Hospital, Basingstoke.

She was an enormously energetic and committed person, seemingly tireless in all her many activities, professional, domestic and recreational. She was devoted to her family and to her large circle of friends, and was a legendary hostess. She maintained her links with her roots in Holland, and actively supported the Anglo-Dutch Society.

Maud was a wonderful and enthusiastic skier, and swimmer. She also engaged in a variety of mildly eccentric projects, such as breeding Great Danes, and growing tomatoes commerciallyt She also created a most beautiful garden at the family home in Winchester.

Her death at such an early age from breast cancer, which she fought courageously and with a determination to enjoy life to the very end, is a terrible loss to her family, and also to her many friends and patients, and to the profession. We will all miss her passionate enthusiasms, her elan and the enormous fun it was to be in her company.

\section{ANTHONY HARBOTT}

Enns Forasman, formerly Professor of Psychiatry at Göteborg University, Sweden

Professor Forssman, who died on 7 September, 1994, aged 82, was recognised nationally and internationally, for his educational and scientific contributions to psychiatry. He recetved a number of scientific awards for his work in particular in biological psychiatry. As one of his co-workers for many years I remember his pride to be elected a fellow of the Royal College of Psychiatrists. UK-psychiatry during the sixties and seventies became a model for Forssman's view on modern psychiatry and many colleagues in the UK became close friends.

Swedish and international psychiatry will certainly miss Hans. He had a marked impact on the development of Nordic psychiatry, particularly during the period when antiintellectual movements tried to destroy scientific progress in this area of medicine.

All of us who were fortunate to work with him will remember Hans as one of the foremost figures in Swedish psychiatry. Professionals worldwide, as well as patients, owe him sincere thanks for his skill, empathy and his high moral standards.

\section{JAN WÄLINDER}

